\title{
REPRESENTAÇÕES DE IN/EXCLUSÃO NA PROVINHA BRASIL ${ }^{1}$
}

Camila Alves de Melo ${ }^{2}$

Clarice Salete Traversini ${ }^{3}$

\begin{abstract}
Resumo: Este trabalho objetiva analisar as representações culturais de alunos incluídos registradas nas Fichas de Correção da Provinha Brasil. Utilizando as noções de In/exclusão (VEIGA-NETO; LOPES, 2011; LOPES, 2007) e de Representação cultural (HALL, 1997), realizamos uma análise documental das Fichas de Correção da Provinha Brasil de 2012 e 2013 de nove escolas de uma rede municipal do sul do Brasil. O estudo mostrou que os alunos incluídos são representados em uma posição de in/exclusão, percebida por duas posturas docentes: (1) permitir que os alunos façam a prova, porém justificando o desempenho pela condição de incluído e (2) não permitir que façam a prova, por serem "de inclusão”. Predominou a segunda opção. Portanto, se os incluídos são desconsiderados nas avaliações em larga escala, possivelmente estarão ausentes das políticas educacionais propostas, gerando outra exclusão.
\end{abstract}

Palavras-chave: Inclusão escolar. Provinha Brasil. Avaliação em larga escala.

\section{REPRESENTATIONS OF IN/EXCLUSION IN THE BRAZILIAN STANDARDIZED TEST FOR SECOND GRADE STUDENTS}

\begin{abstract}
This paper aims to analyze cultural representations of included students as recorded in the Correction Forms of the Brazilian Standardized Test for Second Grade Students. By using the notions of in/exclusion (VEIGANETO; LOPES, 2011; LOPES, 2007) and cultural representation (HALL, 1997), we carried out a documental analysis of the Correction Forms of the Brazilian Standardized Test for Second Grade Students of 2012 and 2013 in nine schools of a municipal network in the south of Brazil. The study showed that included students were represented in an in/exclusion position, which was perceived from two attitudes of teachers: (1) allowing students to do the test, but justifying their performance based on their inclusion condition, and (2) not allowing them to do the test because they are "included". The second option prevailed. Therefore, if included students are not taken into consideration in large-scale evaluations, they will probably be absent in the proposed education policies, thus causing another kind of exclusion.
\end{abstract}

Keywords: School inclusion. Brazilian Standardized Test for Second Grade Students. Large-scale evaluation.

\section{REPRESENTACIONES DE IN/EXCLUSIÓN EN LA "PROVINHA BRASIL"}

Resumen: Este trabajo tiene como objetivo analizar las representaciones culturales de alumnos incluidos registradas en las Fichas de Corrección de la "Provinha Brasil". Empleando las nociones de In/exclusión (VEIGANETO; LOPES, 2011; LOPES, 2007) y de Representación cultural (HALL, 1997), hemos hecho un análisis documental de las Fichas de Corrección de la "Provinha Brasil" del 2012 y del 2013 de nueve escuelas de una red municipal del sur de Brasil. El estudio ha indicado que los alumnos incluidos son representados en una posición de in/exclusión, percibida por dos posturas docentes: (1) el permiso para que los alumnos realicen la prueba, sin embargo justificando el desempeño debido a su condición de incluido y (2) la no permisión para que hagan la prueba, justamente porque son "de inclusión". Ha predominado la segunda opción. Por lo tanto, si a los incluidos se les desconsidera en las evaluaciones a gran escala, posiblemente estarán ausentes de las políticas educacionales propuestas, generando otra exclusión.

Palabras clave: Inclusión escolar. Provinha Brasil. Evaluación a gran escala.

\section{Introdução}

\footnotetext{
${ }^{1}$ Uma primeira versão deste texto foi apresentada e publicada nos anais XI Reunião Científica da Região Sul ANPED Sul, realizada de 24 a 27 de julho de 2016, na Universidade Federal do Paraná, em Curitiba/PR.

${ }^{2}$ Doutoranda e Mestra em Educação pelo Programa de Pós-Graduação em Educação da Universidade Federal do Rio Grande do Sul (PPGEDU/UFRGS).

${ }^{3}$ Professora Associada da Faculdade de Educação da UFRGS e do Programa de Pós-Graduação em Educação da UFRGS; Coordenadora do Grupo de Estudos Educação e Disciplinamento (GPED) e Pesquisadora do Núcleo de Estudos sobre Currículo, Cultura e Sociedade (NECCSO) da UFRGS.
} 
Se as avaliações em larga escala têm como objetivo aferir a qualidade da educação para traçar políticas educacionais, como os alunos incluídos participam dessas avaliações? Vários estudos já se dedicaram a estudar a Provinha Brasil, tais como: Mello (2012), Almeida (2012), Rauen (2011), Cristofolini (2012), Munhoz (2012), Coelho (2012) e Oliveira (2012), com foco nas áreas de linguagem e da matemática. Silva (2011) e Maia (2010) tiveram como foco de investigação a relação entre a Provinha Brasil e o fazer-docente. Gontijo (2012), Esteban (2012) e Morais (2012) se dedicaram a pesquisa com ênfase na política de avaliação. Para acessar a tais estudos recorremos ao Catálogo de Teses e Dissertações da Coordenação de Aperfeiçoamento de Pessoal de Nível Superior (CAPES) ${ }^{4}$, ao Portal de Periódicos CAPES ${ }^{5}$, ao Scientific Electronic Library Online (SciELO) ${ }^{6}$, e ao Google Acadêmico ${ }^{7}$. Entretanto, ao buscar os termos "inclusão" junto com "Provinha Brasil" não encontramos resultados. Tentando com outros termos mais abrangentes (avaliação externa e avaliação em larga escala ao invés de Provinha Brasil), buscamos e selecionamos dois estudos que se aproximam: Silva e Meletti (2014), por tratar dos "estudantes com necessidades educacionais especiais nas avaliações em larga escala: Prova Brasil e ENEM" e de Raimundo (2013) que estudou a “Avaliação externa e educação especial na rede municipal de ensino de São Paulo". No recente "Dossiê - avaliar, diagnosticar, medir: das práticas avaliativas a avaliações em larga escala na Educação Especial", publicado na Revista Educação Especial (2018), o estudo de Kamila Lockmann e Roseli Belmonte Machado (2018) discute a Avaliação Nacional da Alfabetização (ANA) sob as lentes dos Estudos Foucaultianos para argumentar que "as avaliações em larga escala produzem uma espécie de semelhança imaginada, uma vez que, ao considerar algumas variáveis, deixando outras tantas de fora, estabelece invisibilidades, tanto dos alunos com deficiência, quanto do trabalho docente." (LOCKMANN; MACHADO, 2018, p. 890). Com poucas publicações encontradas, a busca evidenciou a carência de estudos que enlacem a temática das avaliações em larga escala e da inclusão escolar. Essa rarefação de escritas reflete a (in)visibilidade do tema nos estudos acadêmicos.

Os questionamentos e as necessidades investigativas nos mobilizaram a propor este estudo que objetiva: analisar as representações culturais sobre alunos incluídos registradas nas Fichas de Correção da Provinha Brasil. Para isso, foi feita uma análise documental de trinta e duas Fichas de Correção, dos anos de 2012 e 2013, de nove escolas de uma rede municipal do

\footnotetext{
${ }^{4}$ Acesso em: https://catalogodeteses.capes.gov.br/catalogo-teses/

${ }^{5}$ Acesso em: http://www.periodicos.capes.gov.br/

${ }^{6}$ Acesso em: http://www.scielo.org/php/index.php

${ }^{7}$ Acesso em: https://scholar.google.com.br/
} 
sul do Brasil. As análises foram feitas a partir das noções de In/exclusão (VEIGA-NETO; LOPES, 2011; LOPES, 2007) e de Representação cultural (HALL, 1997).

Dividimos o texto a partir daqui em três seções: na primeira conceituamos avaliação em larga escala e caracterizamos a Provinha Brasil. Na segunda, apresentamos as "lentes" teóricometodológicas e as análises do material coletado. E, por fim, na terceira, trazemos algumas considerações finais.

\section{Conceito de Avaliação em Larga Escala e Caracterização da Provinha Brasil}

Avaliação em larga escala e avaliação externa são conceitos inseparáveis. Flávia Werle (2010) aponta que "avaliação externa" indica qual é o tipo de avaliação e "em larga escala" indica a abrangência. Para a autora, a "[...] avaliação de larga escala é um procedimento amplo e extensivo, envolvendo diferentes modalidades de avaliação, realizado por agências reconhecidas pela especialização técnica em testes e medidas [...]” (WERLE, 2010, p. 22). Werle (2010) metaforicamente relaciona às avaliações em larga escala às florestas: olhando o conjunto, não é viável determinar características específicas de cada árvore, apenas é possível ter noções gerais sobre floresta. Nesse sentido, florestas e instituições educativas têm muito em comum, tendo em vista a quantidade vasta de árvores que podemos ter em uma floresta e a quantidade de escolas que se têm atuantes hoje no Brasil: são proporções muito grandes para, em uma análise ampla, contemplar as individualidades. Por isso, ter uma avaliação padronizada, em larga escala, pode ser uma alternativa para conhecer "o todo", que é importante, embora deixe de abordar aspectos igualmente relevantes sobre "as partes", estes mais contemplados nas avaliações internas.

A avaliação em larga escala não substitui as avaliações internas: dos alunos feitas pelos professores, da instituição feita pelos funcionários nela lotados etc. São avaliações distintas e complementares, todas com relevante importância para o ambiente escolar. Entretanto, há a crescente problemática das avaliações em larga escala estarem sendo demasiado privilegiadas, a ponto de suas matrizes estarem definindo o que será ensinado nas escolas. Além disso, elas estão adquirindo centralidade para o planejamento das políticas educacionais.

Escolhemos analisar uma avaliação em larga escala voltada para a Educação Básica de âmbito federal, a Provinha Brasil, que teve sua última aplicação no ano de 2016. De responsabilidade do Instituto Nacional de Estudos e Pesquisas Educacionais Anísio Teixeira (INEP), a Provinha Brasil foi instituída no ano de $2007^{8}$, com primeira aplicação em 2008. O objetivo da Provinha Brasil era fornecer dados para o professor sobre o rendimento dos alunos,

\footnotetext{
${ }^{8}$ Instituída pela Portaria Normativa no 10, de 24 de abril de 2007 do Ministério da Educação. Disponível em: $<$ http://pesquisa.in.gov.br/imprensa/jsp/visualiza/index.jsp?jornal=1\&pagina=4\&data=26/04/2007>. Acesso em: 10 abr. 2015 .
} 
tendo função diagnóstica e servindo como subsídio para o planejamento docente. Até o ano de 2011 o exame avaliava os alunos somente quanto às suas habilidades de Leitura, quando então foi incluída a Matemática. Cada uma das duas provas, de Leitura e de Matemática, era composta por vinte questões cada, aplicadas a alunos do $2^{\circ}$ ano do Ensino Fundamental. As aplicações ocorriam duas vezes no ano, chamadas de Teste 1 e Teste 2 , respectivamente no início e final do ano, visando observar as progressões nas aprendizagens. A avaliação era feita por adesão voluntária, ou seja, as escolas optavam se queriam ou não participar da avaliação, embora fosse bastante comum que as Secretarias de Educação, tanto estaduais como municipais, exigissem a aplicação do instrumento. As escolas recebiam os kits de prova impressos, compostos de: caderno do aluno, guia de aplicação e guia de correção e interpretação dos resultados. Após a aplicação das provas, os professores ficavam com os resultados para seu diagnóstico e também os repassavam à direção da escola e às secretarias de educação. A partir de 2013, foi criado um sistema online em que poderiam ser lançados os resultados para obter uma análise descritiva e detalhada do desempenho dos alunos.

Em agosto 2016, sob justificativa de economia com os altos custos de impressão, o Teste 2 da Provinha Brasil foi disponibilizado apenas em versão digital, para que as escolas fizessem a impressão e aplicassem. Decisão que acarretou em problemas para sua continuidade, uma vez que também as escolas sofrem com a falta de recurso. O Ministério da Educação, na época em que disponibilizou as provas somente no formato online, já apontava para incertezas quanto a continuidade da Provinha Brasil. Em 2017, ano em que completaria dez anos de sua criação, não houve disponibilização do material no site do Ministério da Educação, indicando o fim, premeditado, da avaliação.

Nesse cenário, é necessário pontuar que atualmente estão ocorrendo reorganizações no sistema de avaliação em âmbito federal: as avaliações estão "abandonando" seus nomes antigos siglas e nomes fantasia como Avaliação Nacional da Alfabetização (ANA) etc. - em prol da denominação única "Sistema de Avaliação da Educação Básica", com instrumentos avaliativos voltados para cada uma das etapas da Educação Básica. Sendo ou não só uma troca de nomenclatura, nesses tempos de "reorganização", alinhados às mudanças de governo, cabe a crítica ao não aprimoramento das ações já existentes - não só no âmbito das avaliações ou da Educação - que levam ao fim inúmeros projetos e criam-se outros, em substituição e às vezes também na "contramão" daqueles já existentes, produzindo descontinuidades que não qualificam os processos. Salvo todas as críticas que já foram feitas - inclusive por nós e também neste texto - às avaliações em larga escala, acreditamos na necessidade de sua existência como instrumento de conhecimento da população escolar - da floresta como aponta Werle (2010) - que servirão como baliza para a elaboração de políticas educacionais. Além disso, a Provinha Brasil era a 
única avaliação com função diagnóstica voltada para subsidiar o planejamento dos professores e também, muitas vezes, era a primeira experiência dos alunos com um "caderno de prova" e com questões de múltipla escolha, que conforme aponta Camila Alves de Melo (2016) geram reações positivas do contato com esta "novidade" e aprendizagens próprias sobre este artefato da cultura escolar.

\section{As "Lentes" Teórico-Metodológicas e as Análises: Como se Registra a In/Exclusão dos}

\section{Alunos Incluídos?}

Recorremos à noção de in/exclusão e de representação cultural para realizar o presente estudo, entendendo-as como "lentes" (SOMMER, 2005) por nos permitirem perceber como os alunos incluídos são significados nos registros das fichas de correção da Provinha Brasil. Quanto a in/exclusão, nos baseamos nos estudos de Alfredo Veiga-Neto e Maura Corcini Lopes (2011), bem como um estudo solo da Maura Corcini Lopes (2007). Já com a Representação cultural, utilizamos os escritos de Stuart Hall (1997). Tais noções serão descritas na sequência e chamadas às análises posteriormente.

A inclusão escolar é um movimento que gradualmente está se fortalecendo nacional e internacionalmente. Nas últimas décadas a concepção vigente na legislação é a de que os sujeitos incluídos têm o direito de vivenciar a escolarização na rede regular de ensino, junto àqueles ditos "normais" e não isolados em escolas especiais.

A grafia “in/exclusão" vem sendo utilizada por um grupo de pesquisadores da Universidade do Vale do Rio do Sinos, embasados nas compreensões dos termos "inclusão e exclusão" de Robert Castel e nos estudos de Michel Foucault. Dentre eles, destaco Alfredo Veiga-Neto e Maura Corcini Lopes que pontuam que “[...] a in/exclusão se caracteriza pela presença de todos nos mesmos espaços físicos e pelo convencimento dos indivíduos de suas incapacidades e/ou capacidades limitadas de entendimento, participação e promoção social, educacional e laboral." (2011, p. 131). Sendo assim, a in/exclusão é a permanência "flutuante" do sujeito, que participa dos dois processos. A partir do nosso entendimento, um aluno pode estar incluído no ambiente escolar, mas excluído das práticas que nele se estabelecem, flutuando entre a in/exclusão, por motivos que dizem respeito a forma como o outro o vê e o significa. Inclusão e exclusão são "invenções do nosso tempo" (LOPES, 2007, p.11), processos em relação e inseparáveis, pois necessitam um do outro para existirem e articularem-se nas relações sociais. 
A noção de representação cultural ${ }^{9}$ é utilizada partir de Stuart Hall (1997), que a concebe "como importante para a própria constituição das coisas [...]" (HALL, 1997, p. 5) [tradução nossa]. Para o autor, a partilha de significados se dá na cultura e é através da linguagem que atribuímos estes significados. A linguagem funciona como "sistema de representação", pois ao fazermos uso dela "[...] utilizamos sinais e símbolos - podendo ser sons, palavras escritas, imagens produzidas eletronicamente, notas musicais, até objetos - que significam ou representam para outras pessoas nossos conceitos, ideias e sentimentos.” (HALL, 1997, p. 1) [tradução nossa]. Ou seja, ao partilharmos tais significados dentro da cultura, através da linguagem, constituímos um sistema de representações dos objetos. É nessa trama entre linguagem, significado e representação, que situamos a presente análise. A linguagem será aqui entendida em sua forma escrita, através da forma como os professores escrevem sobre seus alunos incluídos.

A metodologia desse estudo utiliza a análise documental e tem como material empírico as Fichas de Correção da Provinha Brasil disponibilizadas pela Secretaria de Educação de uma rede municipal do sul do Brasil. Ao analisarmos as Fichas de 2012 e 2013, percebemos que os professores não utilizavam somente números no espaço reservado ao total de acertos. Eles usavam, também, termos que significavam os alunos avaliados. Nossa atenção voltou-se, então, para analisar os processos de significação que envolvem essa avaliação, ou seja, o que é feito com o aluno incluído quando da aplicação das avaliações em larga escala e como eles são representados, através da linguagem escrita, nas Fichas de Correção. Optamos pela análise documental pois permite "[...] estudar o problema a partir da própria expressão dos indivíduos, ou seja, quando a linguagem dos sujeitos é crucial para a investigação. Nessa situação incluemse todas as formas de produção do sujeito em forma escrita." (LÜDKE; ANDRÉ, 2015, p. 46). Portanto, a linguagem das Fichas de Correção foi entendida como uma forma de representação dos sujeitos.

Ao fazer a análise do material, em um primeiro momento, separamos somente as Fichas de Correção que faziam alguma referência aos alunos incluídos. Sendo assim, o material empírico é composto por trinta e duas Fichas de Correção, referentes a nove escolas das cinquenta e quatro que compõem o sistema educacional de uma rede municipal do sul do Brasil.

A partir das lentes teórico-metodológicas, construímos dois focos de análise: (1) mapear os termos utilizados nas Fichas de Correção para identificar aquele aluno com necessidades educativas especiais, neste texto denominados como "incluídos", e depois (2) problematizar as

\footnotetext{
${ }^{9}$ Além de Hall, muitos outros autores desenvolvem seus conceitos de representação, tais como: Michel Foucault, Roger Chartier, Jean Piaget, Serge Moscovici e outros. Por isso, adjetivamos de "cultural" o conceito de Hall (1997) para delimitar a perspectiva teórica do conceito utilizado.
} 
relações entre as avaliações em larga escala e as representações de in/exclusão na escola. Quanto ao primeiro foco, reunimos no quadro que segue os termos utilizados pelos professores para significar seus alunos:

\section{Quadro 1 - Termos utilizados pelos professores nas Fichas de Correção}

\begin{tabular}{|c|c|c|}
\hline Termos & Possível significado & $\begin{array}{l}\text { Em quantas Fichas de } \\
\text { Correção foi utilizado? }\end{array}$ \\
\hline $\begin{array}{l}\text { NEEs - Down } \\
\text { NEEs - DM }\end{array}$ & $\begin{array}{l}\text { Necessidades Educativas Especiais (NEE) - Síndrome de } \\
\text { Down } \\
\text { Necessidades Educativas Especiais (NEE) - Deficiência } \\
\text { Mental }\end{array}$ & 1 \\
\hline Inclusão & Mesmo do termo utilizado & 1 \\
\hline $\mathrm{NE}$ & Necessidades Especiais & 1 \\
\hline Aluna/o inclusão & Mesmo do termo utilizado & 2 \\
\hline Aluno especial & Mesmo do termo utilizado & 2 \\
\hline Inclusão NEEs & Inclusão - Necessidades Educativas Especiais (NEE) & 2 \\
\hline NEEs & Necessidades Educativas Especiais (NEE) & 2 \\
\hline Aluno de SIR & Aluno de Sala de Integração e Recursos (SIR) & 2 \\
\hline AEE & Atendimento Educacional Especializado (AEE) & 3 \\
\hline $\mathrm{AE}$ & Aluno Especial & 4 \\
\hline Aluno NEEs & Aluno com Necessidades Educativas Especiais (NEE) & 4 \\
\hline SIR & Sala de Integração e Recursos (SIR) & 8 \\
\hline & Total & 32 \\
\hline
\end{tabular}

Fonte: Dados da pesquisa organizados pelas autoras.

É possível ver que ora os professores fazem referência ao aluno e sua condição de incluído, inclusive em alguns casos pontuando qual a característica que o faz "diferente" dos demais (exemplo: “Down”), e ora é referenciado o espaço que ele frequenta ou o serviço que utiliza, referindo-se à SIR e ao AEE. Acreditamos que os alunos identificados são os que a Provinha Brasil chama de "alunos com necessidades educativas especiais" (BRASIL, [entre 2008 e 2015], n.p.), ou seja, alunos que, por motivos específicos, demandam atendimento especializado, planejamentos e atividades adaptadas etc. Demandas essas que não são necessidades daqueles ditos "normais". É importante pontuar que aqueles que são identificados são os que, por inúmeros motivos, podem ter um baixo desempenho justificado pela sua condição de incluído. 
Lopes considera que: "A demarcação da diferença parte do pressuposto orientador que esta pode ser capturada, identificada, (des)velada, nomeada [...]" (2007, p. 12) [grifo nosso]. Esse ato de identificar e nomear a diferença feito pelos professores nas Fichas de Correção, pode ter por finalidade distinguir os alunos que se enquadram na "métrica da normalidade" e os que estão aquém dela. Alunos que, no caso específico, têm garantido seu lugar no grupo que não tem maiores problemas em realizar as avaliações em larga escala e, do lado inverso, os nãohabilitados a participar da mesma forma que os outros das avaliações em larga escala. São "fronteiras imaginárias que definem os autorizados a participarem do lado dos incluídos e os autorizados a participarem do lado dos excluídos." (LOPES, 2007, p. 12). As "fronteiras imaginárias", culturalmente construídas, definem o limite que separa os "normais", naturalmente incluídos, e os "anormais", excluídos que necessitam passar pelo processo de inclusão. Se a inclusão e a exclusão são entendidas como “[...] invenções do nosso tempo. [...] completamente dependentes e necessárias uma para a outra.” (LOPES, 2007, p. 12), é possível afirmar que os sujeitos ocupam um lugar de in/exclusão. Estar na escola não significa ocupar o lugar de inclusão, tendo em vista que a própria forma como nomeamos, identificamos, lidamos e comparamos nossos alunos, pode ser vista como ação excludente dentro de uma proposta escolar/política que deseja (ou que impõe) a inclusão.

A noção de in/exclusão nos impulsionou a problematizar para além dos termos que representam os "alunos incluídos" grafados na ficha de correção da avaliação. Nos ocupamos também em analisar o que é feito com eles durante a aplicação. Após identificar quem eram esses alunos nas Fichas, observamos que das trinta e duas Fichas de Correção analisadas, apenas em dez esses alunos parecem efetivamente fazer a prova. Isso porque os professores registraram o número total de acertos e, quando havia acertos, quais as questões que obtiveram respostas corretas. Entretanto, é importante grifar que na coluna que indica o total de acertos, logo após o número, é colocado o termo que o significa, por exemplo: “0 - AE” (aluno especial). Como se a designação de sua condição de aluno especial justificasse o desempenho. Um exemplo dessa situação pode ser visto na imagem: 


\section{Figura 1 - Ficha de correção Provinha Brasil (1)}

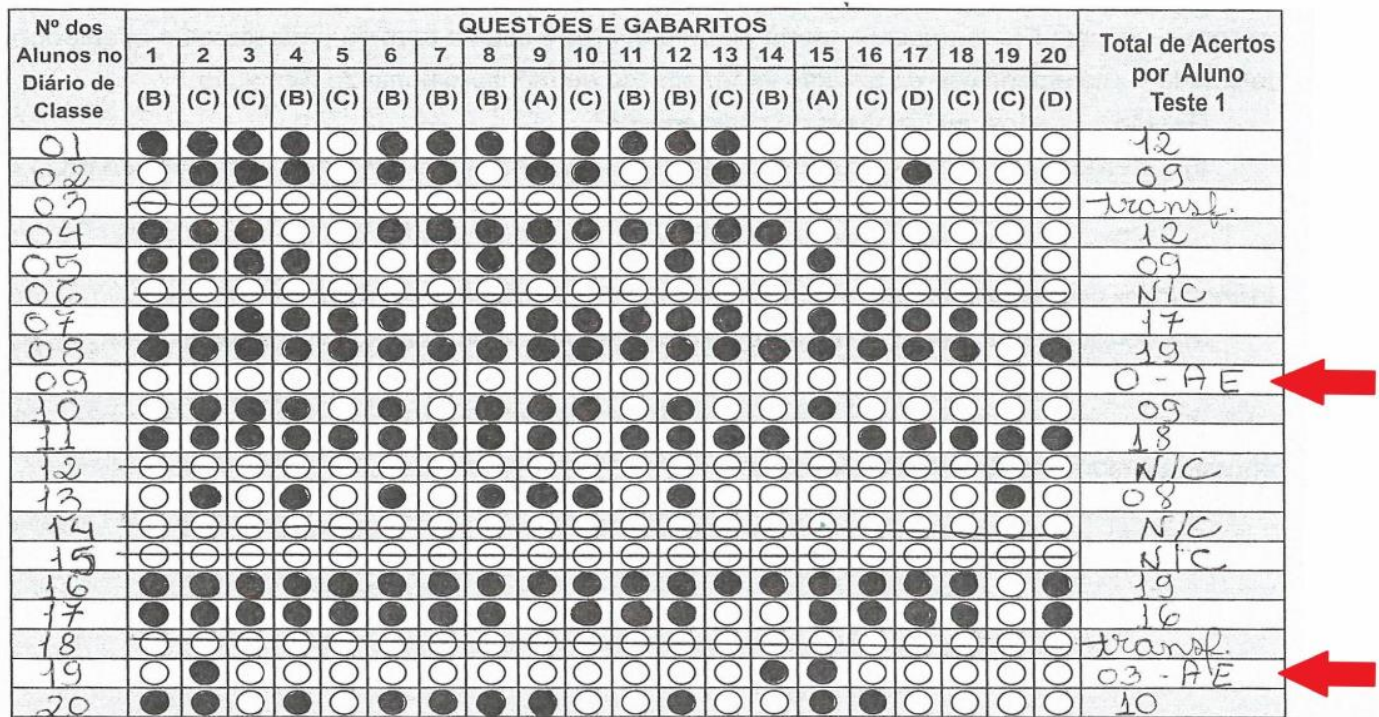

Fonte: grupo de pesquisa.

Ainda sobre o que é feito com os alunos no momento da avaliação, a análise das outras vinte e duas Fichas de Correção, permite inferir que os alunos não fizeram a prova. Isso porque, sobre a linha de marcação de suas respostas há um traço horizontal e no total de respostas o termo que o significa, como na imagem que segue:

\section{Figura 2 - Ficha de correção Provinha Brasil (2)}

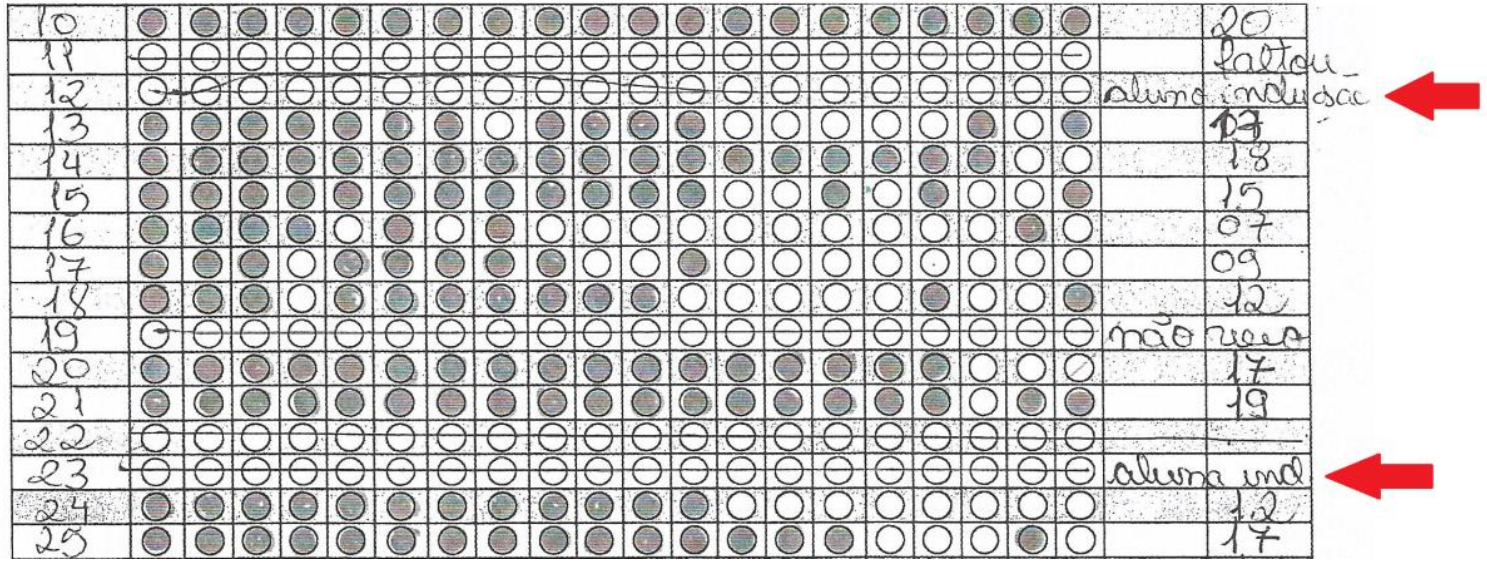

Fonte: grupo de pesquisa.

Também há situações em que no total de respostas não é indicado um número, apenas um traço: 
Figura 3 - Ficha de correção Provinha Brasil (3) ${ }^{10}$

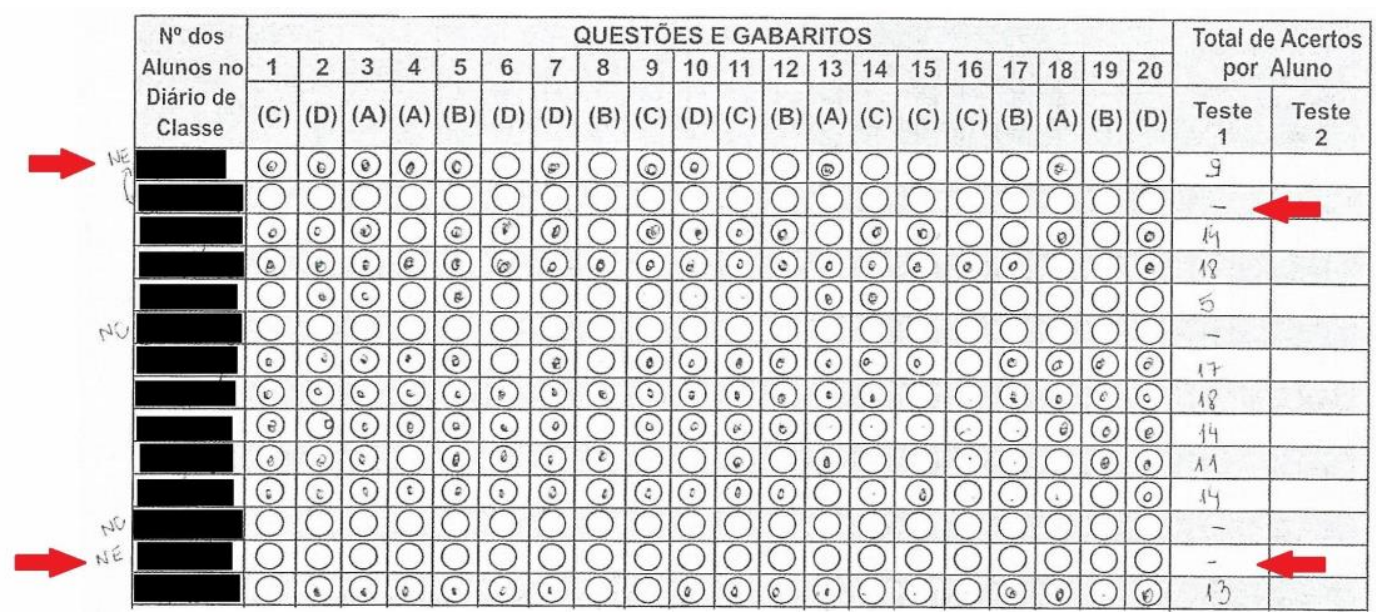

Fonte: grupo de pesquisa.

E, por último, situações em que, ao invés do total de acertos, é colocado o termo que o significa, sem nenhuma anotação de suas respostas:

\section{Figura 4 - Ficha de correção Provinha Brasil (4)}

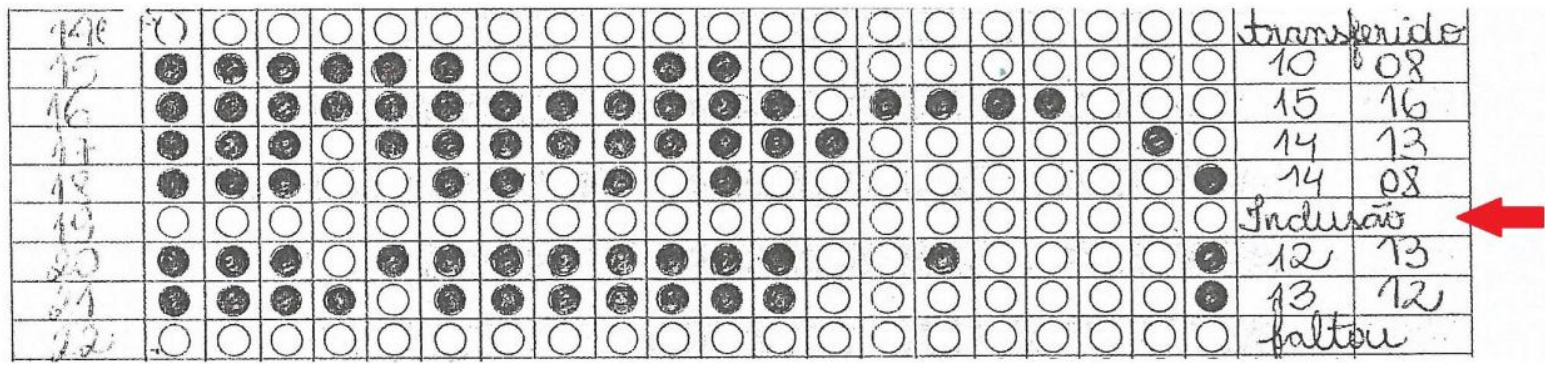

Fonte: grupo de pesquisa.

Dessa maneira, inferindo que esses alunos não fizeram a prova, temos: dez situações em que os alunos incluídos fizeram a prova e vinte e duas em que não a realizaram. A indicação dada pelo INEP, responsável pela avaliação, é que os alunos incluídos realizem a prova. Podendo utilizar, caso necessitem, a SIR e o AEE, conforme consta no site do INEP, nas perguntas e respostas sobre a Provinha Brasil:

23. Alunos com necessidades educativas especiais participam da Provinha Brasil? As crianças com necessidades educativas especiais podem e devem participar da Provinha Brasil, conforme suas possibilidades e utilizando os recursos de acesso oferecidos pela secretaria de educação e pela escola. (BRASIL, [entre 2008 e 2015], n.p.)

O INEP ainda está dando os primeiros passos para pensar uma avaliação que contemple esses alunos. Por enquanto, repassa às Secretarias de Educação, às escolas e aos professores a

\footnotetext{
${ }^{10}$ Os nomes dos alunos registrados nessa ficha de correção foram suprimidos por sigilo ético.
} 
responsabilidade de promover oportunidades igualitárias de participação nas avaliações em larga escala.

As informações anteriores nos remetem ao segundo foco: problematizar as relações entre as avaliações em larga escala e as representações de in/exclusão na escola. Acreditamos que, ao invés de não permitir que o aluno incluído faça a prova, pode-se buscar alternativas para que ele compreenda e acesse o instrumento avaliativo, utilizando recursos materiais e humanos. Entretanto, também é preciso considerar a ótica dos professores: por vezes solitárias em suas turmas, não tem outra opção senão privar os alunos incluídos de um instrumento avaliativo que, sem os aparatos necessários, pouco consegue diagnosticar as suas aprendizagens. Nessa direção, concordamos com Lopes quando afirma "Hoje a inclusão está mais presente, seja para nos amedrontar, seja para nos desafiar em nosso trabalho e dia-a-dia." (2007, p. 14). Não julgamos as atitudes dos professores, apenas procuramos entender quais as razões para as tomadas de decisão com relação aos alunos incluídos nas aplicações das avaliações em larga escala.

Destacamos que a mesma Ficha de Correção da Provinha Brasil foi objeto de reflexão de Esteban (2014), que criticou o modelo proposto por reduzir uma "criança a uma linha": ignora-se a diversidade e se diminui um aluno à simples contagem de seus erros e acertos. A autora também aponta que não só os alunos são invisibilizados pela avaliação, mas também os professores, quando da instituição de uma avaliação que pouco se propõe ao diálogo com os docentes, que somente impõe formas de exercer seu próprio trabalho. Sobre o desempenho dos estudantes, aponta: “Os (maus) resultados são comumente explicados por relações que apontam o próprio sujeito que fracassa [...] como responsável pelo fracasso.” (ESTEBAN, 2014, p. 471). Para nós, o ato da identificação do aluno incluído na Ficha de Correção pode ser visto como uma forma de responsabilizar sua condição (e o sujeito em si) pelo seu desempenho.

Ronca (2013) chama de "efeito perverso" o ato de impedir a presença de alunos ditos “mais fracos" em avaliações como a Prova Brasil (que gera o IDEB) para não baixar a média da escola. Mesmo que a Provinha Brasil seja de uso diagnóstico, não permitir que o aluno faça a prova pode indicar que o professor o compreenda nessa faixa de "alunos mais fracos", que baixariam a média da turma na Provinha, avaliação cujos resultados são enviados às Secretarias de Educação.

Outro aspecto que observamos no estudo das Fichas de Correção diz respeito à possibilidade de ver o fluxo da evasão escolar ainda presentes nas escolas. Pontuamos tal aspecto como importante para a discussão pois é mais uma forma de in/exclusão. Era comum observarmos o registro de: "evadido", "infrequente" e "FICAI", que se refere a Ficha de Comunicação de Aluno Infrequente (FICAI). Nessa direção, Lopes afirma que "O lado perverso da inclusão escolar está em democratizar o acesso à escola, mas não possibilitar que os sujeitos 
ditos diferentes permaneçam nela.” (LOPES, 2007, p. 31). Embora não seja foco das análises nos questionamos: para onde vão esses alunos? As escolas municipais da cidade estudada, em sua maioria, estão localizadas em bairros de periferia e abrigam alunos do seu próprio entorno, que vivem em situação socioeconômica baixa. Nesse sentido, o processo de inclusão, não deve ser pensado somente para aquele aluno que carrega consigo um laudo médico, mas também para o que se encontra em situação de vulnerabilidade social. Os infrequentes são, portanto, mais um dos in/excluídos, tendo em vista que não conseguimos, muitas vezes, promover ações que garantam a sua permanência na escola e o próprio meio em que vive o leva por outros caminhos.

Inferimos também que há a possibilidade de que vários alunos incluídos estejam presentes sem terem sido significados e grafados como tais nas demais Fichas de Correção. O que pode explicitar uma conduta de não distinção entre "normais" e "anormais". Entretanto, ao não identificar aquele que é diferente, também não sabemos de sua presença e de sua efetiva participação no processo de avaliação. E tratar de forma igual os diferentes nos testes de avaliação, bem como em todo processo de ensinar e aprender, pode fortalecer os processos de exclusão ao invés de potencializar a inclusão.

\section{Considerações finais}

Ao finalizar este estudo sobre a representação do aluno incluído nas Fichas de Correção da Provinha Brasil, temos a dizer que ele é representado ora como alguém capaz de fazer a prova, mas que tem seu desempenho justificado pela sua condição e ora como alguém incapaz de realizar a avaliação, porque a sua condição o faz assim. Na maioria dos casos analisados imperou essa segunda representação: ele não realiza a prova. Registra-se nas Fichas de Correção, portanto, o lugar de in/exclusão dos alunos, qual seja: incluídos no ambiente escolar e excluídos das práticas avaliativas que ali ocorrem, por motivos que dizem respeito a como os docentes veem o instrumento avaliativo e a própria inclusão. Assim sendo, "Estar incluído fisicamente no espaço da escola comum não é garantia de estar integrado nas relações que nela se estabelecem.” (LOPES, 2007, p. 31). Nessa conjuntura de in/exclusão, também as avaliações em larga escala, podem ser representadas como um lugar em que não há espaço para o aluno incluído. Nos ritos que envolvem essas avaliações, ainda, cabe pensar, quem pode e quem não pode ser avaliado?

Em nosso grupo de pesquisa, consideramos as avaliações em larga escala como práticas biopolíticas inspirados na noção utilizada por Michel Foucault (2015). A partir disso, os incluídos acabam sendo excluídos do planejamento de políticas educacionais subsidiadas pelas avaliações em larga escala. Foucault utiliza o termo “[...] biopolítica para designar o que faz com que a vida e seus mecanismos entrem no domínio dos cálculos explícitos, e faz do poder-saber um agente de transformação da vida humana” (2015, p. 154). E justifica seu entendimento: “[...] 
não é que a vida tenha sido exaustivamente integrada em técnicas que a dominem e gerem; ela lhes escapa continuamente.". (FOUCAULT, 2015, p. 154).

A partir do autor, consideramos biopolítica como uma forma institucional de gestão da vida do corpo social, ou seja, da população, em especial da escolar. As avaliações em larga escala produzem informações indicando qual parcela da população escolar está atingindo os indicadores desejados e sobre qual são necessárias ações e investimentos para a melhoria. São ações sobre a população de alunos na escola. Portanto, se os incluídos são desconsiderados nas avaliações em larga escala, possivelmente estarão ausentes das ações que delas decorrem, como o planejamento docente e as políticas educacionais. Relembramos que a Provinha Brasil é uma ação diagnóstica voltada para o professor, que não embasou políticas educacionais em nível federal. Entretanto, gerou ações em várias redes de ensino públicas, a exemplo do que mostra o estudo de Artur Gomes de Morais, Telma Leal e Eliane Albuquerque (2009), em que uma rede municipal “[...] utilizou a Provinha para redefinir suas prioridades na formação continuada de alfabetizadores.” (MORAIS; LEAL; ALBUQUERQUE, 2009, p. 301).

Então, se os incluídos na escola estão excluídos das avaliações em larga escala, tornam-se invisíveis para o estabelecimento de políticas educacionais e, novamente, são excluídos. E, se os indicadores de desempenho das avaliações em larga escala estão sendo atrelados à qualidade da educação, como os incluídos, que estão invisíveis, farão parte desse processo?

\section{Referências}

ALMEIDA, Ayane Nazarela Santos de. A competência narrativa na Provinha Brasil: um estudo do desempenho dos estudantes da EMEF Tenisson Ribeiro Aracaju/SE. 2012. 127 p. Dissertação (Mestrado em Letras) - Pós-graduação em Letras, Universidade Federal de Sergipe, São Cristóvão, 2012. Disponível em: <http://bdtd.ufs.br/handle/tede/2336>. Acesso em: 21 nov. 2018.

BRASIL. Instituto Nacional de Estudos e Pesquisas Educacionais Anísio Teixeira. Ministério da Educação. Perguntas Frequentes. [entre 2008 e 2015]. Disponível em: <http://provinhabrasil.inep.gov.br/perguntas-frequentes>. Acesso em: 21 nov. 2018.

BRASIL. Instituto Nacional de Estudos e Pesquisas Educacionais Anísio Teixeira. Ministério da Educação. Provinha Brasil: Guia de Correção. 2014. Disponível em: $<$ http://download.inep.gov.br/educacao_basica/provinha_brasil/kit/2014/provinha_brasil_guia_c orrecao_interpretacao_resultados.pdf $>$. Acesso em: 21 nov. 2018.

COELHO, Flávia Renata Franco Lopes. O que revelam as crianças diante da resolução dos itens de retirar, completar e comparar excluídos no pré-teste da provinha brasil de matemática. 2012. 174 p. Dissertação (Mestrado em Educação) - Programa de Pós-graduação em Educação, Universidade Federal do Estado do Rio de Janeiro, Rio de Janeiro, 2012. Disponível em: $<$ http://educacao.unirio.br/index.php?page=defendidas-em-2012>. Acesso em: 21 nov. 2018.

CRISTOFOLINI, Carla. Refletindo sobre a Provinha Brasil a partir das dimensões sociocultural, linguística e cognitiva da leitura. Alfa, revista de linguística (São José Rio Preto), São Paulo, v. 56, n. $1, \quad$ p. 217-247, 2012. Disponível em: 
$<$ http://www.scielo.br/scielo.php?script=sci_arttext\&pid=S1981-

57942012000100010\&lng=en\&nrm=iso>. Acesso em: 21 nov. 2018.

ESTEBAN, Maria Teresa. A negação do direito à diferença no cotidiano escolar. Avaliação (Campinas), Sorocaba, v. 19, n. 2, p. 463-486, jul. 2014. Disponível em: <http://www.scielo.br/scielo.php?script=sci_arttext\&pid=S1414$40772014000200012 \& \operatorname{lng}=$ pt\&nrm=iso >. Acesso em: 21 nov. 2018.

ESTEBAN, Maria Teresa. Considerações sobre a política de avaliação da alfabetização: pensando a partir do cotidiano escolar. Revista Brasileira de Educação, Rio de Janeiro, v. 17, n. 51, p. 573-592, dez. 2012. Disponível em: $<$ http://www.scielo.br/scielo.php?script=sci_arttext\&pid=S1413-

$24782012000300005 \& \operatorname{lng}=\mathrm{en} \& n r m=$ iso $>$. Acesso em: 21 nov. 2018.

FOUCAULT, Michel. Direito de morte e poder sobre a vida. In: História da Sexualidade I: a vontade de saber. São Paulo: Paz e Terra, 2015.

GONTIJO, Cláudia Maria Mendes. Avaliação da alfabetização: Provinha Brasil. Educação e Pesquisa, São Paulo, v. 38, n. 3, p. 603-622, set. 2012. Disponível em: $<$ http://www.scielo.br/scielo.php?script=sci_arttext\&pid=S151797022012000300005\&lng=en\&nrm=iso>. Acesso em: 21 nov. 2018.

HALL, Stuart. Introduction. In: HALL, Stuart. (Org.). Representation: Cultural Representations and Signifyng Practises. Sage/Open University: London, New Delhi, 1997. p. 1-11.

LOCKMANN, Kamila; MACHADO, Roseli Belmonte. Invisibilidades na Avaliação Nacional da Alfabetização (ANA): os alunos com deficiência e o trabalho docente. Revista Educação Especial, Santa Maria, p. 879-892, out. 2018. Disponível em: <https://periodicos.ufsm.br/educacaoespecial/article/view/33090>. Acesso em: 20 nov. 2018.

LOPES, Maura Corcini. Inclusão escolar: currículo, diferença e identidade. In: LOPES, Maura Corcini; DAL'IGNA, Maria Claudia (Org.). In/exclusão: nas tramas da escola. Canoas: Editora da ULBRA, 2007. p. 11-33.

LÜDKE, Menga; ANDRÉ, Marli E. D. A. A análise documental. In: Pesquisa em Educação: Abordagens Qualitativas. 2. Ed. Rio de Janeiro: EPU, 2015.

MAIA, Marinilda. Provinha Brasil: A utilização e avaliação dos testes de diagnósticos da alfabetização pelos professores. 2010. 165 p. Dissertação (Mestrado em Educação) - Programa de Pós-graduação em Educação, Universidade Federal de Minas Gerais, Belo Horizonte, 2010. Disponível em: <http://www.bibliotecadigital.ufmg.br/dspace/bitstream/handle/1843/FAEC8MDHGQ/2_dissertacao_marinilda.pdf?sequence=1>. Acesso em: 21 nov. 2018.

MELLO, Darlize Teixeira de. Provinha Brasil (ou "provinha de leitura"?): mais "uma avaliação sob medida" do processo de alfabetização e "letramento inicial?". 2012, 433 p. Tese (Doutorado em Educação) - Programa de Pós-Graduação em Educação, Universidade Federal do Rio Grande do Sul, Porto Alegre, 2012. Disponível em: <http://hdl.handle.net/10183/61756>. Acesso em: 21 nov. 2018.

MELO, Camila Alves de. Representações de professores e de alunos sobre a Provinha Brasil. Porto Alegre: UFRGS, 2016, 137 p. Dissertação (Mestrado em Educação) - Programa de PósGraduação em Educação, Faculdade de Educação, Universidade Federal do Rio Grande do Sul, Porto Alegre, 2016. Disponível em: <http://hdl.handle.net/10183/149087>. Acesso em: 21 nov. 2018.

MORAIS, Artur Gomes. Políticas de avaliação da alfabetização: discutindo a Provinha Brasil. Revista Brasileira de Educação, Rio de Janeiro, v. 17, n. 51, p. 551-572, dez. 2012. Disponível 
em:

$<$ http://www.scielo.br/scielo.php?script=sci_arttext\&pid=S141324782012000300004\&lng=en\&nrm=iso>. Acesso em: 21 nov. 2018.

MORAIS, Artur Gomes de; LEAL, Telma Ferraz; ALBUQUERQUE, Eliana Borges Correia. "Provinha Brasil": monitoramento da aprendizagem e formulação de políticas educacionais. Revista Brasileira de Política e Administração da Educação, Goiânia, v. 25, n. 2, p.301-320, maio/ago. 2009. Disponível em: <http://seer.ufrgs.br/rbpae/article/view/19499>. Acesso em: 21 nov. 2018.

MUNHOZ, Danilo Pereira. Provinha Brasil de Matemática: um estudo sobre a aplicação piloto com ênfase no bloco de grandezas e medidas. 2012. 91 p. Dissertação (Mestrado em Educação para a Ciência) - Programa de Pós-graduação em Educação para a Ciência, Universidade Estadual Paulista Júlio de Mesquita Filho, Bauru, 2012. Disponível em: <http://www2.fc.unesp.br/BibliotecaVirtual/DetalhaDocumentoAction.do?idDocumento=489\#>. Acesso em: 21 nov. 2018.

OLIVEIRA, Pollyanna Nunes. A provinha Brasil de matemática e o conhecimento estatístico: instrumento avaliativo a ser utilizado pelo professor?. 2012. 158 p. Dissertação (Mestrado em Educação Matemática e Tecnológica) - Programa de Pós-graduação em Educação Matemática e Tecnológica, Universidade Federal de Pernambuco, Recife, 2012. Disponível em: <http://repositorio.ufpe.br:8080/xmlui/handle/123456789/13031>. Acesso em: 21 nov. 2018.

RAIMUNDO, Elaine Alves. Avaliação externa e educação especial na rede municipal de ensino de São Paulo. 2013. 190 p. Dissertação (Mestrado em Educação) - Programa de Pós-graduação em Educação, Universidade de São Paulo, São Paulo, 2013. Disponível em: <http://www.teses.usp.br/teses/disponiveis/48/48134/tde-11102013-111939/pt-br.php>. Acesso em: 21 nov. 2018.

RAUEN, Fábio José. Avaliação da habilidade de inferência em leitura: estudo de caso com uma questão da provinha Brasil. Linguagem em (dis)curso, Tubarão, v. 11, n. 2, p. 217-240, ago. 2011. Disponível em: <http://www.scielo.br/scielo.php?script=sci_arttext\&pid=S151876322011000200002\&lng=en\&nrm=iso>. Acesso em: 21 nov. 2018.

RONCA, Antonio Carlos Caruso. Avaliação da educação básica: seus limites e possibilidades. Revista Retratos da Escola. Brasília, v. 7, n. 12, p. 77-86, jan./jun. 2013. Disponível em: <http://www.esforce.org.br/index.php/semestral/article/download/262/439>. Acesso em: 21 nov. 2018.

SILVA, Mariana Cesar Verçosa; MELETTI, Silvia Márcia Ferreira. Estudantes com necessidades educacionais especiais nas avaliações em larga escala: prova Brasil e ENEM. Revista Brasileira de Educação Especial, Marília, v. 20, n. 1, p. 53-68, mar. 2014. Disponível em: $\quad<$ http://www.scielo.br/scielo.php?script=sci_arttext\&pid=S141365382014000100005\&lng=en\&nrm=iso>. Acesso em: 21 nov. 2018.

SILVA, Selma Gattass Dias Aires da. Políticas de avaliação para o Ensino Fundamental: a Provinha Brasil e suas implicações na prática docente. 2014. 128 p. Dissertação (Mestrado em Educação) - Programa de Pós-graduação em Educação, Universidade do Estado de Mato Grosso, Cáceres, 2014. Disponível em: <http://www.unemat.br/prppg/educacao/docs/dissertacao/2014/Selma_Gattass_Dias_Aires_da_S ilva.pdf>. Acesso em: 21 nov. 2018.

SOMMER, Luis Henrique. Tomando palavras como lentes. In: COSTA, Marisa Vorraber; BUJES, Maria Isabel Edelweiss (Org.). Caminhos investigativos III: riscos e possibilidades de pesquisar nas fronteiras. Rio de Janeiro: DP\&A, 2005. p. 69-83. 
VEIGA-NETO, Alfredo; LOPES, Maura Corcini. Inclusão, exclusão e in/exclusão. Verve, São Paulo, n. 20, p. 121-13, 2011. Disponível em: <http://revistas.pucsp.br/index.php/verve/article/view/14886/11118>. Acesso em: 21 nov. 2018.

WERLE, Flávia Obino Corrêa. Sistema de avaliação da educação básica no Brasil: abordagem por níveis de segmentação. In: WERLE, Flávia Obino Corrêa (Org.). Avaliação em larga escala: foco na escola. São Leopoldo: Oikos; Brasília: Liber Livro, 2010. 